\title{
Measuring Factors Influencing Progression across the Stages of Readiness to Lose Weight among Overweight and Obese Adolescents
}

\author{
Rosnah Sutan, Asmah Johari, Rozita Hod, M. T. Azmi \\ Department of Community Health, Universiti Kebangsaan Malaysia, Kuala Lumpur, Malaysia \\ Email: rosnah_sutan@yahoo.com
}

How to cite this paper: Sutan, R., Johari, A., Hod, R. and Azmi, M.T. (2017) Measuring Factors Influencing Progression across the Stages of Readiness to Lose Weight among Overweight and Obese Adolescents. Health, 9, 153-171.

http://dx.doi.org/10.4236/health.2017.91011

Received: December 24, 2016

Accepted: January 19, 2017

Published: January 22, 2017

Copyright (c) 2017 by authors and Scientific Research Publishing Inc. This work is licensed under the Creative Commons Attribution International License (CC BY 4.0).

http://creativecommons.org/licenses/by/4.0/

\begin{abstract}
Epidemic incidence of obesity has become one of the public health priorities in disease control prevention. The study aims to determine the prevalence of readiness stages to lose weight among the overweight and obese adolescents and its influencing factors. A cross-sectional study was conducted on 631 adolescents of body mass index for age with z-score $>1$ SD based on World Health Organization growth reference chart. The stages of readiness to lose weight were assessed using Trans-Theoretical Model. Intrinsic and extrinsic factors were collected using self-administered questionnaire. Majority of the respondents were in the action stage (40.3\%) followed by contemplation (26.5\%), preparation (15.5\%), maintenance (11.4\%) and pre-contemplation (6.3\%). Ordinal regression analysis identified significant factors influencing progression across the stages of readiness to lose weight: no junk foods sold in school canteens $(\mathrm{p}=0.005)$, TV viewing time $\leq 2$ hours $(\mathrm{p}=0.001)$, high physical activity means score $(\mathrm{p}<0.001)$ and family encouragement on healthy eating $(p=0.010)$. Majority of adolescents who were overweight and obese were at the action stage of weight reduction. Focusing on extrinsic factors help to improve the effectiveness of weight management intervention.
\end{abstract}

\section{Keywords}

Body Mass Index, Obese, Adolescent, Trans-Theoretical Model, Readiness

\section{Introduction}

The prevalence of overweight and obesity among children and adolescents was noted in increasing trends over the past 30 years, and has become a significant public health concern [1]. Obesity has been shown as strong factor that has association with major health problems such as heart disease, hypertension, type II 
diabetes, numerous types of cancers and sleep apnea [2]. Many strategies have been taken to halt the progression of obesity epidemic, especially in the western. It showed low success rate [3]. The problem of obesity is no longer of developed countries concern, but it has become an alarming problem in developing countries too. Children are increasingly vulnerable to develop overweight and obesity. International Obesity Task Force (IOTF) estimates that a total of 155 million school-age children (5 - 17 years) worldwide are overweight or obese [4].

There is evidence of transmission of obesity among children in developing countries, for example, in Thailand the prevalence of obesity among children aged $5-12$ years has increased from $12.2 \%$ to $15.6 \%$ in just two years [2]. Data from the National Thai Food Consumption Survey showed that the prevalence of overweight and obesity among children aged $3-18$ years was $7.6 \%-9.0 \%$, respectively [5]. In China, adolescents aged $8-18$ years have shown a dramatic increase in obesity prevalence within 20 years, in which, only $2 \%$ of boys and $1 \%$ of girls are overweight or obese in 1985, but in 2005, the prevalence had increased to $14 \%$ for boys and $9 \%$ for girls, which contributed to a total of approximately 21 million children in China [6].

In Malaysia, due to rapid economic and technological advancement in the past three decades has led to an increase in purchasing power and a comfortable atmosphere in our population. Therefore, Malaysians are increasingly engaging in obesogenic behavior, such as high fat diet and at the same practice sedentary lifestyle [7]. These lead to increased prevalence of overweight and obesity among adolescents from $9.5 \%$ in 1994 [8] to $19.6 \%$ in 2004 [9]. It was noted an increase of nearly doubled within 10 years period. The rapid increment is worrying because several studies revealed that the percentage of children who suffer from weight problems and obesity are increasing despite different methods and measurement used to define overweight and obesity, age groups and ethnic composition of the area (urban and rural). A study done among 6239 school children aged 7 - 16 years in Kuala Lumpur found that the prevalence of obesity and overweight was respectively $3.5 \%$ and $6.0 \%$. Prevalence for obese boys was higher compared to girls and the occurrence was noted highest around the period of puberty (11 - 14 years) [8]. There was no significant for ethnicity by gender noted in that study [8], except for higher percentage of Indians faced overweight problem, followed by the Chinese and Malay. The pattern was noted similar inboys and girls. Poh et al. (2004) [10] conducted a study among the adolescent girls and boys aged $12-17$ years in four areas in Peninsular Malaysia and Miri Sarawak, reported that the prevalence of overweight was higher among boys $(20.3 \%)$ compared to girls (17.7\%). However, another study done in 10 randomly selected schools in Malaysia by Narayanan et al. [11] in 2011 showed that the prevalence of obesity among adolescents aged $12-18$ years was $8.4 \%$. More recent longitudinal cohort study of 1361 respondents aged 13 years old enrolling 15 public secondary schools from northern (Perak) and the central (Selangor and Kuala Lumpur) regions of Peninsular Malaysia reported that $15.4 \%$ of them are overweight and $8.5 \%$ are obese [12]. In overall, it showed an 
increasing trend of overweight and obesity among school children in Malaysia.

Helping children and young people in weight management or weight reduction is more complex and challenging than helping adults in managing their weight. Growth and development of children and adolescents as the external factors make weight management is difficult and long-term weight loss into something that is uncertain. Many approached for prevention and interventions have been developed in an attempt to control or reduce weight of the adolescents in various levels such as interventions at the community level, multi-agencies approach, involving policy initiatives, and also through peers at school level [13]. Failure to identify and understand the factors that contribute to successful weight management may be the reason for the ineffectiveness of current preventive interventions. This has been proved by many systematic reviews in obesity intervention among adolescents in which only modest weight loss achieved. A review of 57 randomized controlled trials (RCT) of obesity prevention programs among adolescents, showed only 4 major studies had reported statistical and clinical significant [14]. Another systematic review study has found only 8 out 24 intervention studies were effective [15]. Brown \& Summerbell (2009) [16] in systematic review study from 20 intervention studies had noted only 9 studies showed a significant effect in reducing BMI.

A comprehensive behavioral intervention was defined as a promising intervention in reducing weight in which, extensive changes in lifestyle, modification of attitudes, beliefs and behaviors about food and physical activity [17] [18]. Some studies have suggested that weight management program using an approach that combines diet, physical activity, parental involvement and behavior modification will give better result [19] [20] [21]. A systematic study done by Luttikhuis et al. (2009) reported that the physical activity, eating habit and lifestyle pattern has been recommended as important behavior factors in targeting obesity management and has been used as guidelines for the treatment of obesity in children [22] [23]. Therefore, weight management in the treatment of obesity is not always achieved good results as it needs good commitment by individual in which efforts to modify old habits must be emphasis.

The mechanisms that influence adolescence to apply behavior change towards healthier lifestyle should be understood. Exploring their readiness to change by practicing healthy behavior is very important. Helping clients to change and practice healthy behaviors are an important role for health care providers. Interventions towards behavior change are very helpful in dealing with lifestyle modification for the prevention; management of long-term illness and addiction problems has been highlighted [24]. Understanding the patient's willingness to make changes and understand the barriers for changes has been reported as important element in improving patient compliance and reduces healthcare provider frustration during the intervention program [23].

The concepts of readiness for change have been described for the first time by Prochaska and colleagues in Trans-theoretical Model (TTM) and Stages of Change [25] [26]. TTM describes sequence of behavioral changes in an indivi- 
dual's behavior from unhealthy to healthy. It is a model of intentional change that predicts the likely outcome of the current process of adaptation to the behavior of the "new" derived [25] [26]. There are two main assumptions of this model which the first assumption is willingness to change behavior is not present on everyone and second assumption is behavioral change are complex and progress according to stages [26] [27]. In adolescents, this model has been validated in various health behaviors such as physical activity [27] [28], sedentary lifestyle [29], and consumption of fruit, vegetables and fat intake [30] [31].

According to TTM, one has to show progress through five or six stages of change (SOC) when they desire to have behavior change [25] [26]. The first stages of change is known as pre-contemplation which is one has no intention to change in the future, second is the contemplation which is one proposes to change in the next 6 months, third is preparation stage, in which one aims to change within the next 30 days, the fourth stage is action, which is one has doing something to change but less than 6 months and the last stage is the maintenance where a person has been doing something to change in a period of more than 6 months and maintain it. This study will determine the factors that influencing the progression across the stages of readiness to lose weight among overweight and obese adolescents. The objective of this study was to determine the prevalence of stages of readiness to lose weight among overweight and obese adolescents and factors that influencing the progression across the stages of readiness to lose weight.

\section{Methods}

\subsection{Sample and Procedures}

A cross sectional study was conducted from April-October 2014 involving two out of seven districts in Negeri Sembilan, Malaysia which reported the highest proportion of obesity [32]. Three secondary schools were selected from each selected district by multistage random sampling (Figure 1). Students were screened according to sample unit criterion of body mass index (BMI) for age with z-score of $>1$ SD from WHO Reference 2007 [2]. A total of 2281 students aged 13 to 19 years old were screened and there were 631 overweight and obese students were recruited in the present study. Overweight was defined when z-score in between $>+1 \mathrm{SD}$ and $\leq+2 \mathrm{SD}$. The obesity was defined when $\mathrm{z}$-score of $>+2 \mathrm{SD}$ according to WHO growth reference of 5 - 19 years old [2]. Information about the study and the parents' permission for their adolescents' participation was taken before the data collection. Only students with parental approval and willing to participate in this study were given questionnaire which contains $12 \mathrm{sec}$ tions:

Section 1: Demographic information included the age, gender, race, parental' age, parents' highest educational level, parents' employment status and total household income per month.

Section 2: Anthropometric measurements taken were body weight in kilograms $(\mathrm{kg})$ and height in meters for the calculation of body mass index (BMI). 

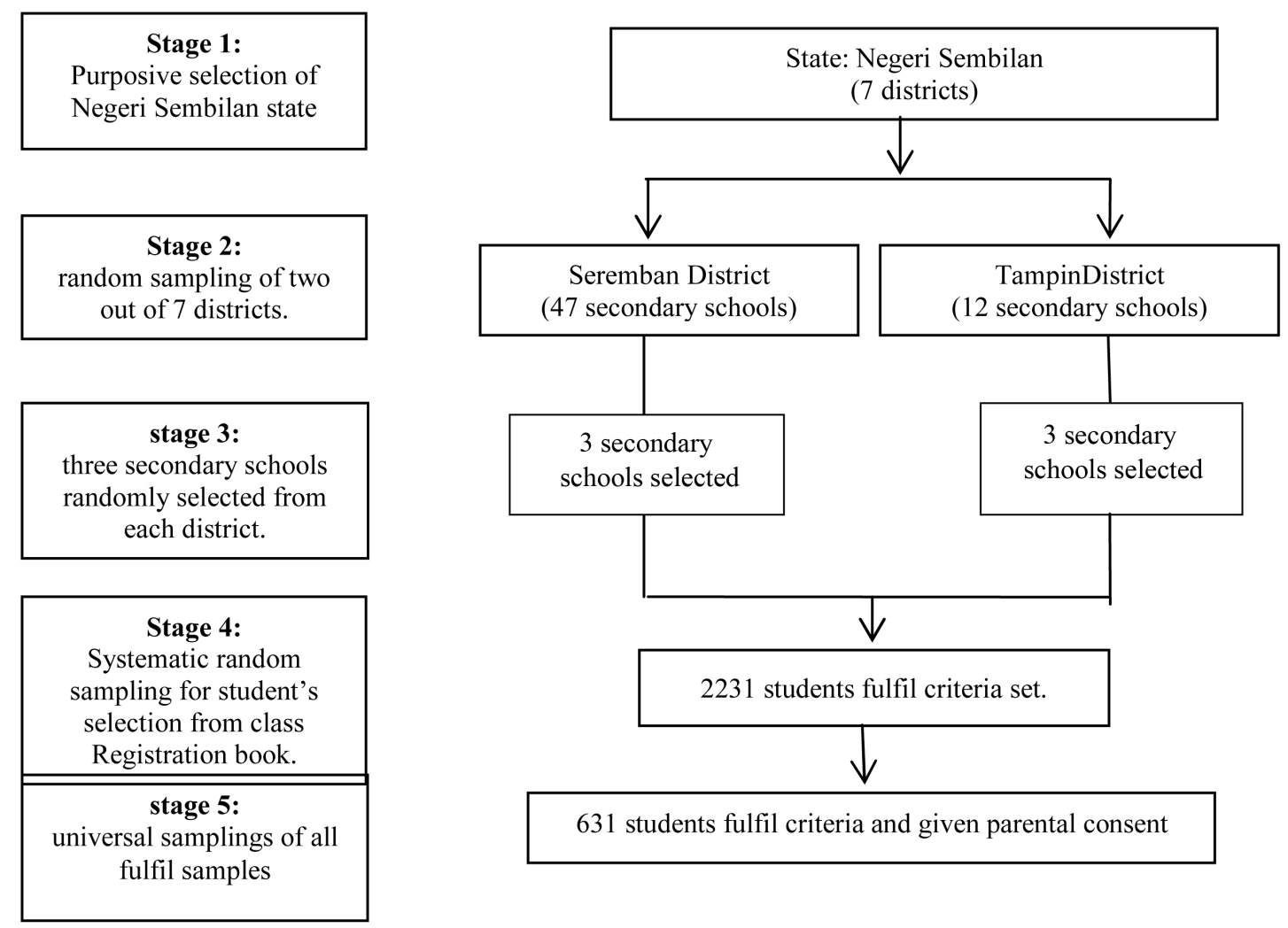

Figure 1. Sampling technique flow chart.

Body weight was measured in a state where students wear school uniforms and socks and was measured using Tanita digital weighing scale with an accuracy of $0.1 \mathrm{~kg}$. The height was also measured while students were in school uniform and socks using SECA stadiometer and recorded at the point nearest to $0.1 \mathrm{~cm}$. BMI-for-age gender specific was calculated by using WHO AnthroPlus software version 1.0.2 [33].

Section 3: Perceived weight status for respondents was assessed by response to the question, "How do you describe your weight?" Response options included 1) slightly underweight, 2) about the right weight, 3) slightly overweight, or 4) very overweight. The variable of interest is misperception of body weight. For example overweight respondent based on BMI-for-age calculations were classified as accurately perceiving his/her weight status if chosen one of the two options: "slightly overweight" or "very overweight". All other descriptions of weight status reflected inaccurate perceptions of weight status. Overweight status in family members were assessed through student responses to questions about obesity in the family. Students are also required to state who is within the family that has an issue with obesity.

Section 4: Physical Activity Questionnaire for Adolescent (PAQ-A)], which has been adapted and modified from the scale created by Kowalski et al. (2004) [34] was used to assessed the mean score of physical activity. This scale consists of nine items, where item 1 is the student leisure time for the last seven days. Students are required to answer a checklist of activities and graded on a 5-point 
scale from "no" graded as 1 to "7 times or more" graded as 5. Mean all the activities in the list of activities calculated to form a composite score for an item 1 . For item $2-8$, student activity were measured during physical education (PE) class, during recess, lunchtime, after school hours, evenings, weekends, and during field. The choice for each items were ranging from a lowest activity "none" (score 1) to the highest activity "6 - 7 times a week" (score 5). For items 8 , students were asked about the frequency of participating in daily physical activity (such as playing sports, games) within a week before with score 1 for answers to "no" and a score of 5 for "always". The mean score for all days of the week are calculated to form a composite score for item 8. Item 9 is used to identify students who have barriers to physical activity (such as illness or any obstacles that prevent them from participating in physical activity as usual) on the previous week. Student physical activity score is the mean of the number of items one to eight. Students were classified into three categories based on the mean of physical activity. Students with a mean score of between $1-2.33$ categorized as having low physical activity, 2.34 - 3.66 as moderate physical activity, and the mean score of 3.67 - 5.0 as having high physical activity. Students were further classified into two categories, high (combining moderate and high physical activity categories) and low. Section 4: Fruits and vegetables intake was measured by asking students the frequency they took fruits and vegetables per months. Optional answers are no serving in a month to five times a day.

Section 5: Television (TV) viewing time was measured by asking students on average how many hours they spent watching TV per day during the school day, weekends and public holidays. Optional answers are range from none to six hours or more.

Section 6: Social support consists of family, peer support and school environment factors.

Section 7: Family support in physical activity is measured by family involvement in supporting adolescents' physical activity using validated questionnaire developed by Norman et al. (2005) [29]. It consists of four questions that assess students' perceptions about the frequency of family members providing support for their physical activity during the past 1 week. This scale has a 5-point score between "never" to "every day". Respondents were classified into two categories i.e. high family support in physical activity and low family support in physical activity with the mean score as the cut-off point of 10.04 .

Section 8: Peer support in physical activity for evaluate peer support in physical activity is a five items scale that evaluate the frequency of peer encouragement and support for students to participate in physical activity in the past one week time, There are five options for each item using a Likert scale scores from one for "never" to five for "every day". Item of this scale has been adapted from the scale of peer support for physical activity that was constructed and validated by Norman et al. (2005) [29]. Peer support in physical activity is also classified into two categories, high and low using a cutoff score of 13.28.

Section 9: Family and peer support in healthy eating is adapted from a scale 
developed and validated by Sallis et al. (1987) [35], which were validated among adolescents. Scale for social support for healthy eating habits consists of ten items was to evaluate the frequency of social support received from parents and friends to eat a healthy diet, using a Likert scale of five scores ranging from one to "never" to score five means "always". Items which are encouraged to measure items one to five and six to ten item is for hurdle measurement received from family and peers to adopt healthy eating habits. It is measured and calculated separately for family and peers. Family support in healthy eating is divided into family encouragement to healthy eating and family discouragement to healthy eating is categorized as low and high encouragement by using the mean value as cutoff point at 16.59 and family discouragement to healthy eating is also categorized as high and low with a mean of 11.95 as the cutoff point. Cut-off point for peer encouragement to healthy eating is 11.63 and the discouragement to healthy eating is 10.69 .

Section 10: The school environment factors are measured by statements that related to the school environment that can stimulate students to adopt a healthy lifestyle, particularly in terms of healthy eating and physical activity. The questions are "Have you seen any posters about physical activity in your school?", "Is there enough sports equipment and games court for physical activity at schoo?" and "Is there junk food and/or sweetened beverage being sold at school canteen. (E.g. sweets, chocolates, nuggets, burgers or sausages)".

Section 11: Self-esteem was measured using the Self-Esteem Scale developed by Rosenberg that has been translated and validated in the Malay language, consists of 10 items related to the overall sense of self or self-acceptance [36] [37]. Items were answered in five-point Likert scale ranging from "strongly disagree" for score 1 and "strongly agree" for score 5. The highest score achieved was 50 and the lowest was 10. The mean value was used as cut-off point at value of 37.9. Respondents with a value of equal and less than 37.9 is categorized as having low self-esteem, respondents with value of more than 37.9 are classified as having high self-esteem.

Section 12: Stages of readiness to lose weight is based on the scale for stages of change (The S-Weight) in assessing the readiness to lose weight for those who are overweight and obese developed by Andrés et al. (2009) [38] consists of five options that are mutually exclusive, among which respondents had to choose in order to be allocated to one of the five stages of change: pre-contemplation (do not intend to lose their weight), contemplation (planning to lose their weight within 6 months), preparation (planning to lose their weight over next 30 days), action (have been making an effort by dieting and exercising to lose their weight for less than 6 months), or maintenance (had successfully maintained their desired weight for more than 6 months).

\subsection{Data Analysis}

Data were analyzed using SPSS (Statistical Package for the Social Sciences) version 20.0. A descriptive statistical analysis for categorical data was presented in frequency and percentage. Chi-squared $\left(\chi^{2}\right)$ test was conducted for bivariate 
analysis. To determine the factors that influence progress across stages readiness to lose weight, ordinal regression analysis was used. The dependent variable "stages of readiness to lose weight" was categorized into more than two categories and ordinal in nature in which the "pre-contemplation" that is the lowest level in stages of readiness to lose weight, while "maintenance" is the most high-level of changes. The ordinal regression was used to find the relationship between two variables when the dependent variables has more than two categories and each category has a set of sequences means that the value of the category is either a "higher" than the previous one, or vice versa [39]. The significant value is taken at $\mathrm{p}<0.05$.

\section{Results}

\subsection{Socio-Demographic Characteristics}

The number of girls $(\mathrm{n}=339,53.7 \%)$ participated in this study were more compared to boys $(\mathrm{n}=292,46.3 \%)$. Students mean age was $14.9 \pm 1.53$ years old. The majority of students were from the age group of $13-14$ years old $(\mathrm{n}=310$, $49.1 \%)$ followed by age group $15-17$ years $(\mathrm{n}=287,45.5 \%)$ and only $34(5.4 \%)$ of students aged 18 - 19 years. Nearly three-quarters of the students were Malays ( $\mathrm{n}=445,70.5 \%)$, followed by 94 Chinese students (14.9\%) and $92(14.6 \%)$ were Indians. Mean age of mothers was $44.94 \pm 5.67$ which was lower compared to the mean age father $(47.99 \pm 6.00)$. For the parents' highest level of education, the majority of students have mothers with secondary education $(55.6 \%)$, followed by diploma and degree levels (37.1\%). A total of 3 respondents $(0.4 \%)$ had mothers who had not received any formal education. Similar finding reported for father's highest level of education, majority of them have fathers with secondary schools education (51.8\%) followed by diploma/degree (41.1\%) and primary school education (6.3\%). Half of the respondent mothers were not working (50.4\%), while $47.8 \%$ had mothers with careers. For father employment status, most of the respondents have parents who are working (88.8\%) compared to only 8.6 who were retired and $2.6 \%$ unemployed. The distribution of the percentage of respondent's monthly household income was almost the same within the groups which $36.8 \%$ of respondents were in the low income category, followed by $33.7 \%$ in the middle-income category and $29.5 \%$ in the high-income category.

\subsection{Stages of Readiness to Lose Weight}

This study showed that about $6.3 \%$ were in pre-contemplation, $26.5 \%$ were in contemplation and $15.5 \%$ were in preparation stage of readiness to lose weight. Respondents in action stage (40.3\%) were noted the highest percentages than others, while respondents who in the maintenance (11.4\%) were the lowest.

\subsection{Relationship between the Stages Readiness to Lose Weight and Independent Variables}

Table 1 displayed the relationship between the stages readiness to lose weight 
Table 1. Association between the stages readiness to lose weight and Independent variables studied.

\begin{tabular}{|c|c|c|c|c|c|c|c|}
\hline \multirow[t]{2}{*}{ Variables } & \multicolumn{5}{|c|}{ Stages of readiness to lose weight $(n=631)$} & \multirow{3}{*}{$x^{2}$} & \multirow{3}{*}{$P$ value } \\
\hline & $\begin{array}{c}\text { PC } \\
(n=40)\end{array}$ & $\begin{array}{c}C \\
(n=167)\end{array}$ & $\begin{array}{c}\text { PR } \\
(n=98)\end{array}$ & $\begin{array}{c}A \\
(n=254)\end{array}$ & $\begin{array}{c}M \\
(n=72)\end{array}$ & & \\
\hline & n (\%) & n (\%) & n (\%) & n (\%) & n (\%) & & \\
\hline \multicolumn{8}{|l|}{ Age } \\
\hline $13-15$ years old & $24(6.1)$ & $88(22.4)$ & $61(15.6)$ & $165(42.1)$ & $54(13.8)$ & 12.33 & 0.015 \\
\hline $16-19$ years old & $16(6.7)$ & $79(33.1)$ & $37(15.5)$ & $89(37.2)$ & $18(7.5)$ & & \\
\hline \multicolumn{8}{|l|}{ Gender } \\
\hline Male & $21(7.2)$ & $62(21.1)$ & $42(14.4)$ & $129(44.2)$ & $38(13.0)$ & 10.01 & 0.040 \\
\hline Female & $19(5.6)$ & $105(31.0)$ & $56(16.5)$ & $125(36.9)$ & $34(10.0)$ & & \\
\hline \multicolumn{8}{|l|}{ Race } \\
\hline Malays & $26(5.8)$ & $109(24.5)$ & $72(16.2)$ & $187(42.0)$ & $51(11.5)$ & 4.39 & 0.356 \\
\hline Non Malays & $14(7.5)$ & $58(31.2)$ & $26(14.0)$ & $67(36.0)$ & $21(11.3)$ & & \\
\hline \multicolumn{8}{|c|}{ Mother's highest education level $(n=628)$} \\
\hline Low & $25(6.3)$ & $110(27.8)$ & $64(16.2)$ & $152(38.5)$ & $44(11.1)$ & 2.51 & 0.643 \\
\hline High & $15(6.4)$ & $56(24.0)$ & $32(13.7)$ & $102(43.2)$ & $28(12.0)$ & & \\
\hline \multicolumn{8}{|c|}{ Mother's employment status $(n=624)$} \\
\hline Unemployed & $21(6.4)$ & $84(25.8)$ & $55(16.9)$ & $133(40.8)$ & $33(10.1)$ & 2.29 & 0.682 \\
\hline Employed & $19(6.4)$ & $81(27.2)$ & $40(13.4)$ & $120(40.3)$ & $38(12.8)$ & & \\
\hline \multicolumn{8}{|c|}{ Father's highest education level $(f=606)$} \\
\hline Low & $26(7.3)$ & $102(28.6)$ & $66(18.5)$ & $127(35.6)$ & $36(10.1)$ & 11.85 & 0.019 \\
\hline High & $13(5.2)$ & $58(23.3)$ & $30(12.0)$ & $117(47.0)$ & $31(12.4)$ & & \\
\hline \multicolumn{8}{|c|}{ Father's employment status $(n=605)$} \\
\hline Unemployed & $3(4.4)$ & $21(30.9)$ & $11(16.2)$ & $25(36.8)$ & $8(11.8)$ & 1.29 & 0.864 \\
\hline Employed & $36(6.7)$ & $139(25.9)$ & $85(15.8)$ & $217(40.4)$ & $60(11.2)$ & & \\
\hline \multicolumn{8}{|c|}{ Average monthly household income $(n=628)$} \\
\hline Low income & $16(6.9)$ & $64(27.7)$ & $39(16.9)$ & $84(36.4)$ & $28(12.1)$ & 2.49 & 0.646 \\
\hline High income & $24(6.0)$ & $103(25.9)$ & $57(14.4)$ & $169(42.9)$ & $44(11.1)$ & & \\
\hline \multicolumn{8}{|l|}{ Body weight status } \\
\hline Overweight & $30(7.7)$ & $104(26.8)$ & $60(15.5)$ & $143(36.9)$ & $51(13.1)$ & 8.67 & 0.070 \\
\hline Obese & $10(4.1)$ & $63(25.9)$ & $38(15.6)$ & $111(45.7)$ & $21(8.6)$ & & \\
\hline \multicolumn{8}{|c|}{ Obesity among family members } \\
\hline Yes & $7(4.5)$ & $39(25.0)$ & $27(17.3)$ & $74(47.4)$ & $9(5.8)$ & 10.01 & 0.038 \\
\hline No & $33(6.9)$ & $128(26.9)$ & $71(14.9)$ & $180(37.9)$ & $63(13.3)$ & & \\
\hline \multicolumn{8}{|l|}{ Weight perception } \\
\hline Accurate & $24(6.6)$ & $99(27.3)$ & $53(14.6)$ & $148(40.8)$ & $39(10.7)$ & 1.18 & 0.882 \\
\hline Not accurate & $16(6.0)$ & $68(25.4)$ & 45 (16.8) & $106(39.6)$ & $33(12.3)$ & & \\
\hline
\end{tabular}




\section{Continued}

$\begin{array}{llllllll}\text { Yes } & 19(6.2) & 75(24.4) & 51(16.6) & 134(43.5) & 29(9.4) & 5.30 & 0.258 \\ \text { No } & 21(6.5) & 92(28.6) & 47(14.6) & 119(37.0) & 43(13.4) & & \end{array}$

Self-esteem

$\begin{array}{llllllll}\text { Low } & 19(6.2) & 87(28.2) & 53(17.2) & 124(40.3) & 25(8.1) & 7.56 & 0.109 \\ \text { High } & 21(6.5) & 80(24.8) & 45(13.9) & 130(40.2) & 47(14.6) & & \end{array}$

Fruits and vegetables intake (minimum of 3 servings/day)

$\begin{array}{llllllll}\text { Yes } & 29(5.8) & 141(28.2) & 77(15.4) & 199(39.8) & 54(10.8) & 4.78 & 0.311 \\ \text { No } & 11(8.4) & 26(19.8) & 21(16.0) & 55(42.0) & 18(13.7) & & \end{array}$

Mean score of Physical activities

\begin{tabular}{|c|c|c|c|c|c|c|}
\hline Low & $17(5.4)$ & $72(22.9)$ & $38(12.1)$ & $147(46.7)$ & $41(13.0)$ & 16.63 \\
\hline High & $23(7.3)$ & $95(30.1)$ & $60(19.0)$ & $107(33.9)$ & $31(9.8)$ & \\
\hline
\end{tabular}

TV viewing time

$$
\begin{aligned}
& \leq 2 \text { hours/day } \\
& >2 \text { hours/day }
\end{aligned}
$$

$$
21(11.2)
$$

$68(36.2)$

38 (20.2)

$19(4.3)$

99 (22.3)

$60(13.5)$

$50(26.6)$

$11(5.9)$

42.83

0.001

Poster on physical activities

Yes
No
ealthy eating

Yes

Adequacy of sport facilities

Yes

$\begin{array}{ll}35(6.3) & 142(25.6) \\ 5(6.5) & 25(32.5)\end{array}$

87 (15.7)

228 (41.2)

$62(11.2)$

$11(14.3)$

$26(33.8)$

$10(13.0)$

Junk foods sold at school canteen

Yes

$\begin{array}{ll}26(5.3) & 140(28.5) \\ 14(10.1) & 27(19.4)\end{array}$

84 (17.1)

198 (40.2)

$14(10.1)$

$56(40.3)$

44 (8.9)

0.001

Family support on physical activity

Low

$\begin{array}{ll}30(8.2) & 116(31.6) \\ 10(3.8) & 51(19.3)\end{array}$

$62(16.9)$

127 (34.6)

$32(8.7)$

26.99

127 (48.1)

$40(15.2)$

Peer support on physical activity

Low
High
port on healthy eating

Family support on healthy eating

$\begin{array}{lll}24(6.9) & 111(32.1) & 58(16.8) \\ 16(5.6) & 56(19.6) & 40(14.0)\end{array}$

$121(35.0)$

$32(9.2)$

18.75

0.001

Encouragement

$\begin{array}{llllllll}\text { Low } & 27(9.2) & 99(33.6) & 45(15.3) & 97(32.9) & 27(9.2) & 27.43 & 0.001 \\ \text { High } & 13(3.9) & 68(20.2) & 53(15.8) & 157(46.7) & 45(13.4) & & \end{array}$

Discouragement

Low

$27(8.4)$

$93(29.0)$

47 (14.6) 


\section{Continued}

High $\quad 13(4.2) \quad 74(23.9) \quad 51(16.5) \quad 138(44.5) \quad 34(11.0)$

Peer support on healthy eating

Encouragement

$\begin{array}{llllllll}\text { Low } & 27(8.5) & 90(28.4) & 55(17.4) & 111(35.0) & 34(10.7) & 11.62 & 0.020 \\ \text { High } & 13(4.1) & 77(24.5) & 43(13.7) & 143(45.5) & 38(12.1) & & \\ \text { Low } & & & & & & \\ \text { High } & 22(6.8) & 94(29.2) & 49(15.2) & 127(39.4) & 30(9.3) & 4.78 & 0.311 \\ & 18(5.8) & 73(23.6) & 49(15.9) & 127(41.1) & 42(13.6) & & \end{array}$

Note: $\mathrm{PC}=$ Pre-contemplation, $\mathrm{C}=$ Contemplation, $\mathrm{PR}=$ Preparation, $\mathrm{A}=$ Action, $\mathrm{M}=$ Maintenance. Chi-square test with level of significance $\leq 0.005$.

and independent variables studied. The Chi square test was used to analyze the relationship between the stages of readiness to lose weight and independent variables. There was a statistically significant relationship between the stages of readiness to lose weight and age $\left(\chi^{2}=12.33, \mathrm{p}=0.015\right)$, gender $\left(\chi^{2}=10.01, \mathrm{p}=\right.$ $0.040)$, father's highest level of education $\left(\chi^{2}=11.85, \mathrm{p}=0.019\right)$ and obesity status among family members $\left(\chi^{2}=10.01, \mathrm{p}=0.038\right)$, mean score of physical activity $\left(\chi^{2}=16.63, \mathrm{p}=0.002\right)$, TV viewing time $\left(\chi^{2}=42.83 ; \mathrm{p}=0.001\right)$, junk food sold at school canteen $\left(\chi^{2}=22.60, \mathrm{p}=0.001\right)$, family support on physical activity $\left(\chi^{2}=26.99, \mathrm{p}=0.001\right)$ and peer support on physical activity $\left(\chi^{2}=18.75, \mathrm{p}=\right.$ $0.001)$, family support on healthy eating $\left(\chi^{2}=27.43, \mathrm{p}=0.001\right)$ and peer encouragement on healthy eating $\left(\chi^{2}=11.62, \mathrm{p}=0.020\right)$. Highest percentage differences were noted in the contemplation stage, for age categories and gender. It was noted that high percentage difference was found in action stage for father's highest level of education, obesity status among family members, TV viewing time, mean score of physical activity, family support in physical activity and both encouragement by family and peers in healthy eating. For the variable on junk foods selling at school canteen, it was noted that the big difference in percentage between the categories was seen significant at maintenance stage.

\subsection{The Factors Influencing the Progression across the Stages of Readiness to Lose Weight}

The factors influencing the progression across the stages of readiness to lose weight are shown in Table 2. All independent variables that were statistically significant and comply with assumption of ordinal regression which was the assumption of parallel lines were included in the analysis. From Table 2, respondents from schools that did not sell junk foods in school canteens were more readiness to progress to a higher level of readiness to lose weight compared to respondents in schools that sell junk foods in school canteens [Wald $=7.735, p=$ 0.005], respondents who watch TV two hours or less per day were more likely to progress to a higher level of readiness to lose weight compared to respondents who watch TV more than 2 hours (Wald $=10.085, \mathrm{p}=0.001$ ). Respondents with high mean score of physical activity were more likely to progress to a higher 
Table 2. Multivariate analyses for factors influencing the progression across the stages of readiness to lose weight (ordinal regression model).

\begin{tabular}{|c|c|c|c|c|c|c|}
\hline & \multirow{2}{*}{$\begin{array}{l}\text { parameter } \\
\text { Estimates }\end{array}$} & \multirow{2}{*}{$\begin{array}{c}\text { Standard } \\
\text { error }\end{array}$} & \multirow{2}{*}{ Wald } & \multirow{2}{*}{ P value } & \multicolumn{2}{|c|}{$\begin{array}{l}\text { 95\% Confident } \\
\text { Interval }\end{array}$} \\
\hline & & & & & Lower & Upper \\
\hline \multicolumn{7}{|c|}{ Stages of readiness to lose weight } \\
\hline Pre-contemplation & -5.598 & 0.791 & 50.095 & $<0.001$ & -7.148 & -4.048 \\
\hline Contemplation & -1.370 & 0.269 & 25.985 & $<0.001$ & -1.896 & -0.843 \\
\hline Preparation & -0.713 & 0.255 & 7.808 & 0.005 & -1.213 & -0.213 \\
\hline Action & 2.026 & 0.358 & 32.097 & $<0.001$ & 1.325 & 2.726 \\
\hline \multicolumn{7}{|l|}{ Gender } \\
\hline Male & 0.108 & 0.139 & 0.603 & 0.438 & -0.165 & 0.381 \\
\hline Female & $0^{\mathrm{a}}$ & . & . & . & . & . \\
\hline \multicolumn{7}{|l|}{ Age } \\
\hline $13-15$ years old & 0.134 & 0.140 & 0.925 & 0.336 & -0.139 & 0.408 \\
\hline $16-19$ years old & $0^{\mathrm{a}}$ & . & . & . & . & . \\
\hline \multicolumn{7}{|c|}{ Obesity among family members } \\
\hline Yes & 0.143 & 0.156 & 0.840 & 0.359 & -0.163 & 0.449 \\
\hline No & $0^{\mathrm{a}}$ & & . & . & . & . \\
\hline \multicolumn{7}{|l|}{ Junk foods at school canteen } \\
\hline Yes & -0.498 & 0.179 & 7.735 & $0.005^{\star}$ & -0.848 & -0.147 \\
\hline No & $0^{\mathrm{a}}$ & . & . & . & . & . \\
\hline \multicolumn{7}{|l|}{ TV viewing time } \\
\hline$\leq 2$ hours/day & 0.432 & 0.136 & 10.085 & $0.001^{*}$ & 0.165 & 0.699 \\
\hline$>2$ hours/day & $0^{\mathrm{a}}$ & . & . & . & . & . \\
\hline \multicolumn{7}{|l|}{ Activity physical mean score } \\
\hline Low & -0.597 & 0.158 & 14.363 & $<0.001^{\star}$ & -0.906 & -0.288 \\
\hline High & $0^{\mathrm{a}}$ & . & . & . & . & . \\
\hline \multicolumn{7}{|c|}{ Family support in physical activity } \\
\hline Low & -0.150 & 0.152 & 0.978 & 0.323 & -0.449 & 0.148 \\
\hline High & $0^{\mathrm{a}}$ & . & . & . & . & . \\
\hline \multicolumn{7}{|c|}{ Peer support in physical activity } \\
\hline Low & -0.235 & 0.153 & 2.350 & 0.125 & -0.536 & 0.065 \\
\hline High & $0^{\mathrm{a}}$ & . & . & . & . & . \\
\hline \multicolumn{7}{|c|}{ Family encouragement in healthy eating } \\
\hline Low & -0.373 & 0.145 & 6.621 & $0.010^{*}$ & -0.657 & -0.089 \\
\hline High & $0^{\mathrm{a}}$ & . & . & . & . & . \\
\hline \multicolumn{7}{|c|}{ Peer encouragement in healthy eating } \\
\hline Low & -0.101 & 0.144 & 0.493 & 0.483 & -0.382 & 0.181 \\
\hline High & $0^{\mathrm{a}}$ & . & . & . & $\cdot$ & . \\
\hline
\end{tabular}

Level of significance $\leq 0.05$. ${ }^{\text {a }}$ This parameter is set to zero because it is redundant. 
level of readiness to lose weight compared to respondents who have a mean low score for physical activity (Wald $=14.363, \mathrm{p}<0.001$ ) and respondents with high mean score of healthy eating encouragement were more likely to progress to a higher level of readiness to lose weight compared to respondents who received low family encouragement in healthy eating (Wald $=6.621, \mathrm{p}=0.010$ ).

\section{Discussion}

In this study, it was found that there were extrinsic factors that significantly affect the progress across the stages of readiness to lose weight. These influencing factors were high mean score of physical activity, no selling of junk foods at school canteens, family encouragement for healthy eating practice and watching TV two hours or less a day. High mean score of physical activity was noted a major factor influencing overweight and obese students to advance to higher stages of readiness in weight reduction. The overweight and obese students with high mean score of activity physical were almost two times more likely to progress to higher stages of readiness to lose weight compared to overweight and obese students who have low mean score of physical activity. Regular physical activity was an important element in the treatment of obesity in line with changes in eating behavior has been proven inearlier study [40]. An effective strategy to burn calories using physical activity plays an important role in balancing the energy imbalance caused by weight gain and the occurrence of obesity has been explained [41] [42] [43]. Meta-analysis on efficacy of physical activity intervention reveals that exercise intervention reduced body weight, BMI, lowering body fat percentage and waist circumference [44]. Therefore, adolescents who were engaged with high mean score for physical activity were more likely to progress to higher stages of readiness to lose weight.

No selling of junk foods at the school canteen was found affecting the progress of overweight and obese students to advance to a higher stages of readiness to lose weight. Students from schools who did not sell high-calorie foods in the school canteen was shown one half times more likely to progress to a higher level of readiness to lose weight than those students with presents high-calorie foods selling at the school canteen. Nutrition environment in schools has been identified as one of the factors that affect nutrition of children and adolescents [45] [46] [47]. Earlier studies have shown that home, school and community environment, contribute to potential access to high fat contents foods and foods with high-sugar contents were the major obstacles in maintaining a healthy weight [48] [49]. Finding of present study support the earlier studies, in which no selling of high-calorie foods in the school canteen was important factor for overweight and obese students to be likely to progress to a higher level of readiness to lose weight. Student mealtime was shorter during school time; therefore they did not have time to make a good choice and encouraged them to buy or consume foods that are served in the school cafeteria [50] [51]. Earlier qualitative focus group discussion (FGD) studies among adolescents in schools also showed that their food choices are influenced mainly by hunger, food desirable, food offer- 
ings, and the amount of time available to eat [48] [52]. Karimi et al. [51] in qualitative research through FGD among adolescent girls aged 13 - 15 years in Iran, found that students who responded to question on "when hot-dogs are easily available at school and are cheaper to buy than other snacks, of course I will prefer them over other foods", showed that the adolescents prone choose foods they like or that have better taste than healthy foods if served together. Therefore to ensure overweight and obese adolescents progress to higher stages of change for readiness to lose weight, the sale of foods that is high in fat and calories should be strictly controlled or restricted at school canteen.

Another modifiable factors showed significant in present study was the TV viewing for two hours or less a day. In a cross-sectional study by Braithwaite et al. (2013) [52] which examines the relationship between TV watching time and BMI among 207,672 adolescents aged 13 - 15 years from 37 countries found that more than $89 \%$ of adolescents watch TV more than an hour. The risk of overweight or obesity increases to $10 \%-27 \%$ among children and adolescents who watched one to three hours of TV every day. Present study supported Braithwaite et al. (2013) [52] study that concluded longer TV watching time was positively associated with increased BMI. An intervention study using lifestyle changes among 111 overweight and obese adolescents reported that the amount of TV watching time or video gaming decreased among respondents who successfully lose weight compared to adolescents who reported increased body weight with increase in TV watching time [52] [53]. Traveras et al. (2007) [54] showed that the adolescents who are younger, aged 10 to 14 years were more likely to modify theirs TV viewing time as compared to adolescents aged 15 to 18 years if recommended by their health care practitioner.

While teenagers are often seen as making their own decisions, the results of present study showed that, high family encouragement to healthy eating affect the progress of overweight and obese adolescents to advance to higher stages of readiness to lose weight. Overweight and obese adolescents who have high family encouragement to healthy eating is almost one and a half times more likely to progress to a higher level of readiness to lose weight than those who received low family encouragement on healthy eating. A comprehensive literature review reported a family who support and encourage healthy eating helps teens to modify their behavior towards healthy food intake and keen to lose weight [55]. Parents have a strong influence on the behavior of children's nutrition and the development of their eating habits by determining the availability and access to food in the house, fix the rules and conditions regarding the intake of food, and also act as a role model to their children [55]. Providing support and family encouragement, in healthy food preparation at home will create suitable for adolescents who are overweight and obese to be willing to change their eating habits. Taveras et al. [54] stated that parents and families need to participate in a weight management intervention programs especially for children or adolescents aged 14 years and below, where the influence of adults seems to be still profound.

A cross-sectional study conducted by Rhee et al. (2005) [56] showed that par- 
ents who have overweight and obese teenagers were more ready to change compared to parents of teenagers with normal weight. Present study findings support earlier study by Cobb (2011) which measured the readiness to change among parents, children and adolescents aged 7 to 17 years, that found parent and child readiness to change was a predictor for BMI [57]. This shows the important role of parents in motivating the youth to be more ready to lose weight.

This study is not without limitation, using cross-sectional study design would not able to assess the temporal or determine cause and effect (causality). A teenager who is ready to lose weight before increasing his physical activity or practicing high physical activity leads to lose weight is not able to shown in present study. Age of students enrolled in this study was 13 - 19 years of age, which did not represent the adolescents as a whole. Only Government secondary schools were selected and not covering for private schools which are mostly among the affordable affluent family may not have same determinant.

\section{Conclusion}

The findings of this study indicated the factors which affect the overweight and obese adolescents to progress to higher stages of readiness to lose weight were high mean score of physical activity, no sale of junk foods at school canteen, TV viewing time for two hours or less a day and family encouragement in promoting healthy eating. The results of this study hopefully will be able to give input for program weight management interventions and a follow-up study in the future should be conducted to strengthen the intervention program in order to increase the healthy lifestyle practice among overweight and obese adolescents.

\section{Acknowledgements}

The authors would like to thank to the Ministry of Education, Education Department of Negeri Sembilan and the District of Seremban and District of Tampin Education Officers, schools, teachers, students and parents. An acknowledgement goes to the Research Ethical Committee Universiti Kebangsaan Malaysia Medical Centre who approved and funded the study.

\section{Disclosure Policy}

The authors declare that there is no conflict of interest regarding the publication of this paper.

\section{References}

[1] Ogden, C.L., Carroll, M.D., Curtin, L.R., Lamb, M.M. and Flegal, K.M. (2010) Prevalence of High Body Mass Index in US Children and Adolescents, 2007-2008. Journal of American Medical Association, 303, 242-249. https://doi.org/10.1001/jama.2009.2012

[2] WHO (2003) Obesity and Overweight Facts. World Health Organization, Geneva. www.who.int/dietphysi-calactivity/publications/facts/obesity

[3] Wolk, R. and Somers, V.K. (2006) Obesity-Related Cardiovascular Disease: Implica- 
tions of Obstructive Sleep Apnea. Diabetes, Obesity and Metabolism, 8, 250-260. https://doi.org/10.1111/j.1463-1326.2005.00508.x

[4] International Obesity Task Force (2002) Childhood Obesity. http://www.iotf.org/childhoodobesity.asp

[5] Jitnarin, N., Kosulwat, V., Rojroongwasinkul, N., Boonpraderm, A., Haddock, C.K. and Poston, W.S. (2011) Prevalence of Overweight and Obesity in Thai Population: Results of the National Thai Food Consumption Survey. Eating Weight and Disorder, 16, e242-e249. https://doi.org/10.1007/BF03327467

[6] Ji, C.Y. and Cheng, T.O. (2009) Epidemic Increase in Overweight and Obesity in Chinese Children from 1985 to 2005. International Journal of Cardiology, 132, 1-10. https://doi.org/10.1016/j.ijcard.2008.07.003

[7] Tee, E.S. (1999) Nutrition in Malaysia: Where Are We Heading? Malaysian Journal of Nutrition, 5, 87-109.

[8] Kashmini, K. (1997) Prevalence of Overweight and Obesity among School Children Who Were Aged between 7-16 Years amongst the 3 Major Ethnic Groups in Kuala Lumpur, Malaysia. Asia Pacific Journal of Clinical Nutrition, 6, 172-174.

[9] Lekhraj Rampal, G.R., Sidik, S.M., Rampal, S., Jie, D.W.Y., Lee, C.P., Shya, L.J. and Shun, S.Y. (2007) Prevalence of Overweight among Secondary School Students in Klang District, Selangor. Malaysian Journal of Nutrition, 13, 1-8.

[10] Poh, B.K., Ismail, M.N., Ong, H.F., Norimah, A.K., Safiah, M.Y. and Zafrullah, S. (2004) Energy Requirements of Malaysian Adolescents. Final Report for IRPA 0602-02-0096 Research Project, Kuala Lumpur: Department of Nutrition and Dietetics, Faculty of Allied Health Sciences, Universiti Kebangsaan Malaysia.

[11] Narayanan, P., Ong, L.M. and Omar, M. (2011) Do the Prevalence and Components of Metabolic Syndrome Differ among Different Ethnic Groups? A Cross-Sectional Study among Obese Malaysian Adolescents. Metabolic Syndrome and Related Disorders, 9, 389-395. https://doi.org/10.1089/met.2011.0014

[12] Hazreen, M.A., Su, T.T., Jalaludin, M.Y., Dahlui, M., Chinna, K., Ismail, M., Murray, L., et al. (2014) An Exploratory Study on Risk Factors for Chronic Non-Communicable Diseases among Adolescents in Malaysia: Overview of the Malaysian Health and Adolescents Longitudinal Research Team Study (The MyHeART Study). BMC Public Health, 14, S6. https://doi.org/10.1186/1471-2458-14-S3-S6

[13] Jelalian, E. and Hart, C.N. (2009) Pediatric Obesity. In: Roberts, M.C. and Steele, R.G., Eds., Handbook of Pediatric Psychology, Vol. 4, Guilford Press, New York, 446-463.

[14] Thomas, H. (2006) Obesity Prevention Programs for Children and Youth: Why Are Their Results So Modest? Health Education Research, 21, 783-795. https://doi.org/10.1093/her/cyl143

[15] Floodmark, C.E., Marcus, C. and Britton, M. (2006) Interventions to Prevention Obesity in Children and Adolescents: A Systematic Literature Review. International Journal of Obesity, 30, 579-589. https://doi.org/10.1038/sj.ijo.0803290

[16] Brown, T. and Summerbell, C. (2009) Systematic Review of School-Based Interventions That Focus on Changing Dietary Intake and Physical Activity Levels to Prevent Childhood Obesity: An Update to the Obesity Guidance Produced by the National Institute for Health and Clinical Excellence. Obesity Review, 10, 110-141. https://doi.org/10.1111/j.1467-789X.2008.00515.x

[17] Halberstadt, J., Makkes, S., de Vet, E., Jansen, A., Nederkoorn, C., van der BaanSlootweg, O.H. and Seidell, J.C. (2013) The Role of Self-Regulating Abilities in Long-Term Weight Loss in Severely Obese Children and Adolescents Undergoing 
Intensive Combined Lifestyle Interventions (HELIOS); Rationale, Design and Methods. BMC Pediatrics, 13, 41. https://doi.org/10.1186/1471-2431-13-41

[18] Hill, J.O. and Wyatt, H. (2002) Outpatient Management of Obesity: A Primary Care Perspective. Obesity Research, 10, 124S-130S. https://doi.org/10.1038/oby.2002.205

[19] Anderson, P. and Butcher, K. (2006) Childhood Obesity: Trends and Potential Causes. The Future of Children, 16, 19-45. https://doi.org/10.1353/foc.2006.0001

[20] Caprio, S. (2006) Treating Child Obesity and Associated Medical Conditions. The Future of Children, 16, 209-224. https://doi.org/10.1353/foc.2006.0002

[21] Goldberg, J. and Kiernan, M. (2005) Innovative Techniques to Address Retention in a Behavioral Weight-Loss Trial. Health Education Research, 20, 292-298. https://doi.org/10.1093/her/cyg139

[22] Oude, L.H., Baur, L., Jansen, H., Shrewsbury, V.A., O’Malley, C., Stolk, R.P. and Summerbell, C.D. (2009) Interventions for Treating Obesity in Children. The Cochrane Database of Systematic Reviews, 21, CD001872. https://doi.org/10.1002/14651858.CD001872.pub2

[23] American Diabetes Association (ADA) (2006) Position Statement of the American Dietetic Association: Individual-, Family-, School- and Community-Based Interventions for Pediatric Overweight. Journal of American Dietetic Association, 106, 925-945. https://doi.org/10.1016/j.jada.2006.03.001

[24] Zimmerman, G.L., Olsen, C.G. and Bosworth, M.F. (2000) A "Stages of Change" Approach to Helping Patients Change Behavior. American Family Physician, 6 , 1409-1416.

[25] Prochaska, J. and DiClemente, C. (1983) Stages and Processes of Self-Change of Smoking: Toward an Integrative Model of Change. Journal of Consulting and Clinical Psychology, 51, 390-395. https://doi.org/10.1037/0022-006X.51.3.390

[26] Prochaska, J. and Velicer, W. (1997) The Trans-Theoretical Model of Health Behaviour Change. American Journal of Health Promotion, 12, 38-48. https://doi.org/10.4278/0890-1171-12.1.38

[27] Berry, T., Naylor, P.J. and Wharf-Higgins, J. (2005) Stages of Change in Adolescents: an Examination of Self-Efficacy, Decisional Balance, and Reasons for Relapse. Journal of Adolescent Health, 37, 452-459. https://doi.org/10.1016/j.jadohealth.2004.09.019

[28] Pirasteh, A., Hidarnia, A., Asghari, A., Faghihzadeh, S. and Ghofranipour, F. (2008) Development and Validation of Psychosocial Determinants Measures of Physical Activity among Iranian Adolescent Girls. BMC Public Health, 8, 150-160. https://doi.org/10.1186/1471-2458-8-150

[29] Norman, G.J., Sallis, J.F. and Gaskins, R. (2005) Comparability and Reliability of Paper and Computer-Based Measures of Psychosocial Constructs for Adolescent Physical Activity and Sedentary Behaviors. Research Quarterly for Exercise and Sport, 76, 315-323. https://doi.org/10.1080/02701367.2005.10599302

[30] Huang, Y.-J., Wong, S.H., Salmon, J. and Hui, S.S. (2011) Reliability and Validity of Psychosocial and Environmental Correlates Measures of Physical Activity and ScreenBased Behaviors among Chinese Children in Hong Kong. International Journal of Behavioral Nutrition and Physical Activity, 8, 16. https://doi.org/10.1186/1479-5868-8-16

[31] Zabinski, M.F., Norman, G.J., Sallis, J.F., Calfas, K.J. and Patrick, K. (2007) Patterns of Sedentary Behavior among Adolescents. Health Psychology, 26, 113-120. https://doi.org/10.1037/0278-6133.26.1.113

[32] Institute for Public Health (IPH) (2011) National Health and Morbidity Survey 
2011 (NHMS 2011) Vol. II: Non Communicable Diseases.

[33] WHO (2009) Anthro Plus for Personal Computers Manual: Software for Assessing Growth of the World's Children and Adolescents. WHO, Geneva.

[34] Kowalski, K.C., Crocker, P.R.E. and Donen, R.M. (2004) The Physical Activity Questionnaire for Older Children (PAQ-C) and Adolescents (PAQ-A) Manual. College of Kinesiology University of Saskatchewan, Saskatoon, 11-15.

[35] Sallis, J.F., Grossman, R.M., Pinski, R.B., Patterson, T.L. and Nader, P.R. (1987) The Development of Scales to Measure Social Support for Diet and Exercise Behaviors. Preventive Medicine, 16, 825-836. https://doi.org/10.1016/0091-7435(87)90022-3

[36] Rosenberg, M. (1965) Society and the Adolescent Self-Image. Princeton University Press, Princeton, 326. https://doi.org/10.1515/9781400876136

[37] MohdJamil, B.H.Y. (2006) Validity and Reliability Study of Rosenberg Self-Esteem Scale in Seremban School Children. Malaysian Journal of Psychiatry, 15, 35-39.

[38] Andrés, A., Saldaña, C. and Gomez-Benito, J. (2009) Establishing the Stages and Processes of Change for Weight Loss by Consensus of Experts. Obesity, 17, 17171723. https://doi.org/10.1038/oby.2009.100

[39] Hosmer, D.W. and Lemeshow, S. (2000) Applied Logistic Regression. Ed Ke-2. John Wiley and Sons, New York. https://doi.org/10.1002/0471722146

[40] Parizkova, J. and Hills, A. (2001) Childhood Obesity: Prevention and Management. CRC Press, Boca Rotan.

[41] Gerberding, J.L. and Marks, J.S. (2004) Making America Fit and Trim-Steps Big and Small. American Journal of Public Health, 94, 1478-1479. https://doi.org/10.2105/AJPH.94.9.1478

[42] Foreyt, J. (2005) Need for Lifestyle Intervention: How to Begin. American Journal of Cardiology, 96, 11-14. https://doi.org/10.1016/j.amjcard.2005.05.009

[43] Chaput, J.P., Klingenberg, L., Rosenkilde, M., Gilbert, J.A., Tremblay, A. and Sjödin, A. (2011) Physical Activity Plays an Important Role in Body Weight Regulation. Journal of Obesity, 2011, Article ID: 360257. https://doi.org/10.1155/2011/360257

[44] Stoner, L., Rowlands, D.M., Credeur, D., Hamlin, M., Gaffney, K. and Matheson, A. (2016) Efficacy of Exercise Intervention for Weight Loss in Overweight and Obese Adolescents: Meta-Analysis and Implications. Sports Medicine, 46, 1737-1751. https://doi.org/10.1007/s40279-016-0537-6

[45] American Heart Association (2005) A Nation at Risk: Obesity in the United States. Robert Wood Johnson Foundation, Princeton.

[46] Koplan, J.P., Liverman, D.T. and Draak, V.I. (2006) Committee on Prevention of Obesity in Children and Youth. Preventing Childhood Obesity: Health in the Balance. Institute of Medicine, National Academies Press, Washington DC.

[47] Story, M., Kaphingst, K.M. and French, S. (2006) The Role of Schools in Obesity Prevention. Future Child, 16, 109-142. https://doi.org/10.1353/foc.2006.0007

[48] O’Dea, J. (2003) Why Do Kids Eat Healthful Food? Perceived Benefits of and Barriers to Healthful Eating and Physical Activity among Children and Adolescents. Journal of the American Dietetic Association, 103, 497-501.

[49] Booth, M.L., Wilkenfeld, R.L., Pagnini, D.L., Booth, S.L. and King, L.A. (2008) Perceptions of Adolescents on Overweight and Obesity: The Weight of Opinion Study. Journal of Paediatrics and Child Health, 44, 248-252. https://doi.org/10.1111/j.1440-1754.2007.01267.x

[50] Monge-Rojas, R., Garita, C., Sánchez, M. and Muñoz, L. (2005) Barriers to and Motivators for Healthful Eating as Perceived by Rural and Urban Costa Rican Adoles- 
cents. Journal of Nutrition Education and Behavior, 37, 33-40. https://doi.org/10.1016/S1499-4046(06)60257-1

[51] Karimi-Shahanjarini, A., Omidvar, N., Bazargan, M., Rashidian, A., Majdzadeh, R. and Shojaeizadeh, D. (2010) Iranian Female Adolescent's Views on Unhealthy Snacks Consumption: A Qualitative Study. Iran Journal of Public Health, 39, 92 101.

[52] Braithwaite, I., Stewart, A.W., Hancox, R.J., Beasley, R., Murphy, R., et al. (2013) The Worldwide Association between Television Viewing and Obesity in Children and Adolescents: Cross Sectional Study. PLoS ONE, 8, e74263. https://doi.org/10.1371/journal.pone.0074263

[53] Skelton, J.A., Buehler, C., Irby, M.B. and Grzywacz, J.G. (2012) Where Are Family Theories in Family-Based Obesity Treatment? Conceptualizing the Study of Families in Pediatric Weight Management. International Journal of Obesity, 36, 891-900. https://doi.org/10.1038/ijo.2012.56

[54] Taveras, E.M., Sobol, A.M., Hannon, C., Finkelstein, D., Wiecha, J. and Gortmaker, S.L. (2007) Youths' Perceptions of Overweight-Related Prevention Counseling at a Primary Care Visit. Obesity, 15, 831-836. https://doi.org/10.1038/oby.2007.594

[55] Golan, M. and Crow, S. (2004) Parents Are Key Players in the Prevention and Treatment of Weight-Related Problems. Nutrition Review, 62, 39-50. https://doi.org/10.1111/j.1753-4887.2004.tb00005.x

[56] Rhee, K.E. (2005) Factors Associated with Parental Readiness to Make Changes for Overweight Children. Pediatrics, 116, e94-e101. https://doi.org/10.1542/peds.2004-2479

[57] Cobb, J.E. (2011) Child and Parent Readiness to Change in a Clinical Sample of Obese Youth. Psychology Dissertations Paper 76. http://digitalarchive.gsu.edu/psych_diss/76

Submit or recommend next manuscript to SCIRP and we will provide best service for you:

Accepting pre-submission inquiries through Email, Facebook, LinkedIn, Twitter, etc. A wide selection of journals (inclusive of 9 subjects, more than 200 journals)

Providing 24-hour high-quality service

User-friendly online submission system

Fair and swift peer-review system

Efficient typesetting and proofreading procedure

Display of the result of downloads and visits, as well as the number of cited articles

Maximum dissemination of your research work

Submit your manuscript at: http://papersubmission.scirp.org/

Or contact health@scirp.org 